\title{
SOBRE MARX Y AMÉRICA LATINA (OTRA VEZ) A PROPÓSITO DE UN ARTÍCULO DE HERMANN GÜENDEL
}

\section{ABOUT MARX AND LATIN AMERICA (AGAIN) A REPLY TO HERMANN GÜENDEL'S PAPER}

\author{
George I. García \\ Universidad de Costa Rica
}

Recibido: 3 de setiembre, 2013 • Aceptado: 11 de diciembre, 2013

Resumen: Este escrito polemiza con el artículo "Marx sobre América Latina, revisión crítica de una enunciación eurocentrada", de Hermann Güendel. Se argumenta que el presunto eurocentrismo de este Marx surge desde ciertos sesgos y problemas de interpretación sobre la obra de este autor alemán.

Palabras clave: Karl Marx, América Latina, eurocentrismo.

Abstract: This writing debates Hermann Güendel's paper "Marx sobre América Latina, revisión crítica de una enunciación eurocentrada". Hence, it is here argued that Marx's alleged Eurocentrism only emerges from certain biases and problems in the interpretation of the work of this German author.

Keywords: Karl Marx, Latin America, Eurocentrism.

A mi crítico le parece, sin embargo, poco. A todo trance quiere convertir mi esbozo histórico sobre los orígenes del capitalismo en Europa occidental en una teoría histórico-filosófica sobre la que se hallan sometidos fatalmente todos los pueblos, cualesquiera

que sean las circunstancias históricas que en ella concurran. Karl Marx, Carta a la redacción de "Los Anales de la Patria", 1877. 

artículo "Marx sobre América Latina, revisión crítica de una enunciación eurocentrada", del profesor Hermann Güendel (Güendel, 2011). Sorprendido, digo, no porque no conociera el tipo de crítica que se expresa en sus páginas, sino por su enunciante, un hombre con una importante trayectoria de lucha política y un compromiso por pensar desde la izquierda; si a esto sumamos que es actualmente un referente académico en Costa Rica respecto a la tradición marxista, sus apreciaciones sobre estos temas merecen una particular atención.

Pero, más allá de dicho artículo, el mito del Marx eurocéntrico circula como lugar común en la academia de pos-Guerra Fría y se ha acentuado conforme diversas corrientes pos y decoloniales, siguiendo posiciones derivadas de Nietzsche y de algunos posestructuralistas, por lo que han ido ganando espacio en las universidades latinoamericanas. Varios autores, entre los que destaca Edward Said, han insistido sobre esta interpretación, a pesar de que esta ha sido reiteradamente rebatida desde hace más de dos décadas (Said, 1990).

Por ello, retomo aquí argumentos que, aunque ya no son nuevos, parecieran sistemáticamente invisibilizados y marginados. Divido mi alegato en tres partes: primeramente, me refiero a la periodización sobre la producción teórica de Marx respecto al tema de las sociedades periféricas; luego, me refiero a varios estereotipos reproducidos en dicho artículo respecto a las concepciones de la historia en este teórico y finalmente, argumento en favor de abordar el análisis de la historia mundial y latinoamericana desde las bases establecidas por la concepción de la historia del "Marx maduro".

\section{Karl Marx: rupturas y continuidades}

Güendel afirma que "todo discurso de conocimiento es una enunciación específica que se realiza desde una perspectiva" (Güendel, 2011, p. 94). Sin embargo, el abordaje del artículo no se muestra consecuente con dicho planteamiento: una enunciación se da siempre en un contexto sociohistórico concreto, con uno o más enunciantes concretos y uno o más destinatarios concretos. Al hablar de un "Marx" fuera de estos factores, se mistifica al autor y se invisibilizan las condiciones de producción de sus enunciaciones, así como las rupturas y contradicciones entre estas, suponiendo, por el contrario, la estaticidad de su 
producción teórica. Es una visión deudataria de la noción de sistema como construcción ideal; tal perspectiva, muy común en la historiografía tradicional de la filosofía, funciona como un mecanismo deshistorizador.

Así, el meollo de la crítica de Güendel, como en general de quienes acusan a Marx de eurocéntrico, radica en una operación interpretativa, según la cual, Marx ya había elaborado toda su concepción de la historia en La ideología alemana, o cuando más en el Manifiesto comunista. Contra esta visión, valga recordar que la composición del corpus de Marx ha sido interpretada de varios modos a lo largo de los últimos 130 años; fue precisamente Engels quien buscó unificar apuntes dispersos -algunos más elaborados, otros muy preliminares - del ya difunto Marx, para crear "una obra orgánica y lo más completa posible" (Musto, 2011, p. 22): los tomos 2 y 3 de El capital. Además, sistematizó a través de libros como Anti-Dühring o Ludwig Feuerbach y El fin de la filosofía clásica alemana, los que él consideraba eran los fundamentos del método dialéctico y la visión comunista del mundo.

Posteriormente, la II Internacional (1889-1914) inventó el "marxismo" sobre las bases de la lectura de Engels, pero a la vez la recargó de cientificismo y de los rasgos más deterministas, utilizando ciertos aspectos de las investigaciones de Marx a modo de ideología política. La tesis del derrumbe inevitable del capitalismo se convirtió en el elemento central de esta interpretación, a la vez que

las afirmaciones de Marx, destinadas a delinear los principios dinámicos del capitalismo y, más en general, a describir una tendencia de desarrollo, fueron transformadas en leyes históricas universalmente válidas, de las cuales se podía inferir, hasta en sus detalles, el curso de los acontecimientos (Musto, 2011, p. 25).

Hasta el día de hoy, la gran mayoría de quienes hablan sobre Marx, o marxismo, lo hacen desde las coordenadas ideológicas planteadas por la II Internacional, organización cuya importancia en la reivindicación de las clases trabajadoras de antaño es, por lo demás, innegable.

A partir de discusiones políticas acaecidas posteriormente, autores como Korsch y Althusser -el primero polemizando contra el cientificismo de la II Internacional, el segundo en el marco de la desestalinización del 
marxismo europeo- diferenciaron distintas fases en la obra de Marx ${ }^{1}$. Dado el tema que nos ocupa, no hace falta profundizar sobre estas propuestas específicas de periodización; la del segundo, en particular, ha tenido mucha difusión en lengua castellana. Para efectos de la relación de la producción teórica de Marx con América Latina, ya en una introducción de 1972, Pedro Scaron -el célebre coordinador de la traducción de El capital, llevada a cabo por Siglo XXI — planteó una periodización respecto al tratamiento de Marx sobre América Latina y otras zonas periféricas. Dicho autor encuentra tres fases: la primera, entre 1847 y 1856, es la que traen a colación quienes califican a Marx como colonialista, período durante el cual él y Engels "combinan el repudio moral a las atrocidades del colonialismo con la más o menos velada justificación teórica del mismo" (Marx y Engels, 1978, p. 6)²; es la época de los famosos artículos sobre la India, así como de su valoración positiva de la invasión estadounidense hacia territorios mexicanos.

Durante la segunda fase, entre 1856 y 1864, Marx y Engels denunciaron los atropellos de las potencias colonialistas, y reivindicaron las luchas de los pueblos colonizados. Según Scaron, en este período los autores de marras no revisaron sus concepciones teóricas respecto a las relaciones entre las potencias y el mundo colonial y semicolonial. Finalmente, la tercera fase empieza en 1864 y se prolonga hasta la muerte de Marx. El evento determinante sería la fundación de la I Internacional, a partir de la cual, el autor de El capital, establece vínculos que le permiten una comprensión de primera mano de las zonas periféricas (Marx y Engels, 1978, p. 7-9).

De modo similar, Enrique Dussel, otro teórico latinoamericano a quien difícilmente podría acusarse de eurocéntrico, ha sostenido la tesis de que solo a partir de los borradores luego conocidos como Grundrisse, llegó Marx a su concepción definitiva, la cual estima fundamental para comprender a América Latina en el sistema mundial'. Néstor Kohan coincide en observar un "viraje" en la teoría de la historia de Marx, ya muy claramente en la década de 1860 (Kohan, 1998, p. 227-254), mientras que las recientes investigaciones de Kevin Anderson, basadas en la revisión de la nueva

1 Véase, por ejemplo, Korsch (2011, p. 37-45) y Althusser (1972).

2 Énfasis del original. Es de notar que Güendel cita esta antología, pero no prestó atención a esta periodización en su introducción, o al menos no la mencionó.

3 Véase, por ejemplo, Dussel (1985), (1988) y (1990). 
edición de las obras completas de Marx y Engels, indican que ya a partir de 1857 el primero había empezado a formular una concepción multilineal de la historia, la cual no solamente desarrolló en los Grundrisse, sino también en diversos artículos periodísticos. En este sentido, los estudios de Anderson corregirían la periodización de Scaron, mostrando la unidad teórica entre el segundo y el tercer período en esta.

Llama la atención que las fuertes críticas que hace Marx contra la colonización (incluso en sus artículos de inicios del año1850 y posteriores) no hayan sido objeto de los análisis pos y decoloniales, como sí lo fueron sus observaciones de la primera fase. El entusiasmo con el que Marx recibió, por ejemplo, las revueltas en la India y China en 1857 no tiene nada que ver con el reciente estereotipo de "pensador eurocentrado"4. Tampoco parecieran enunciaciones eurocentradas las condenas de Marx en 1861 a la intromisión británica, española y francesa en México. El artículo de Güendel, con justa razón, cita fragmentos marxianos, que quince años atrás, habían avalado la invasión estadounidense; sin embargo, no menciona textos en los que el teórico alemán califica la intervención de esas tres potencias como "una de las empresas más monstruosas jamás registradas en los anales de la historia internacional" (Marx y Engels, 1978, p. 256) e ironiza sobre las intenciones de estas, apuntando que "indudablemente el medio más original de fortalecer a un gobierno [el mexicano, que les debía dinero, GG] consiste en el secuestro de sus ingresos y territorios por la violencia” (Marx y Engels, 1978, p. 253).

La principal potencia europea -y mundial— por aquellos tiempos, no aparece para el Marx de entonces, como una vanguardia a la que hubieran de sometérsele las áreas periféricas, para beneficio y "progreso" de estas. Por el contrario, denuncia a "la moderna diplomacia británica, con toda su santurrona hipocresía, su furia desatada ante los débiles, su servilismo ante los fuertes y su absoluto desprecio por el derecho de gentes" (Marx y Engels, 1978, p. 271). Por supuesto, esta actitud de Marx contra las potencias europeas, y a favor de un país periférico, no cuadra con los prejuicios eurocéntricos que Güendel le atribuye a la totalidad de la obra de Marx;

4 Al respecto puede consultarse Ahmad (2008), p. 228-230. Sobre los abusos británicos en China, consúltese Marx y Engels (1979, XV, p. 232-235). 
mucho menos da para catalogarlo como "pensador del imperio británico" o "entusiasta de la expansión imperial".

Contrástese los anteriores ejemplos con el juicio del autor costarricense:

Las características estructurales de ese discurso están constituidas por lugares de enunciación eurocéntricos que recogen, desde la diferencia de la posición imperial, categorías de diferenciación con la región colonizada como lo son: raza, razón y poder político, generando entonces un discurso saturado no de reflexión, sino de prejuicios y ligerezas, productos de el desinterés (Güendel, 2011, p. 95).

Como se hace evidente, Güendel parte de la premisa de que hay un discurso de Marx sobre América Latina, el cual se estructura desde el eurocentrismo; pero para sostener esto, remite a textos anteriores a 1855 -los atinentes a la invasión yanqui a territorios mexicanos- y al artículo sobre Bolivar y Ponte, sobre el cual nos referiremos en el siguiente apartado.

O sea, deja por fuera unos dieciocho años de la mejor producción intelectual de Marx, una omisión que no impide que el autor asegure que "Marx nunca logrará entender, por estar centrado en una enunciación categorialmente eurocentrada e imperial, los significados reales de los procesos y los sujetos sobre la significación histórica de América Latina” (Güendel, 2011, p. 101).

\section{Estereotipos persistentes: linealidad, teleología, progreso}

Güendel tiene sobrada razón al señalar que el texto de Marx sobre Bolívar fue hecho de modo apresurado, y bajo un interés puramente laboral. También señala muy acertadamente que, en dicho texto, Marx no aplicó su método científico al análisis de la situación histórica latinoamericana, y que posiblemente en Bolívar vio solo un aventurero al estilo de Napoleón III; ciertamente el artículo del socialista alemán carece de simpatía alguna por la figura de "El Libertador". Con lo que no podemos concordar es con las razones que Güendel le atribuye a tales yerros: este indica como motivos no solo al eurocentrismo, sino a una exaltación de la raza, la razón y el poder

5 Estos epítetos los adopta de Arturo Chavolla en Güendel (2011, p. 97). 
político. Más todavía, afirma que Marx siguió una filosofía especulativa de la historia ${ }^{6}$, en el sentido que este explícitamente rechazó una y otra vez, como en el fragmento que hemos citado aquí a modo de epígrafe.

¿Por qué Marx no se ocupó de América Latina? Primeramente, no creo razonable desestimar las circunstancias biográficas: pasó la mayor parte de su vida intentando descubrir la estructura de la economía capitalista, mientras luchaba contra la pobreza y la enfermedad (la propia y de su familia), a la vez que participaba decisivamente en política. Por ello, no solamente no publicó sobre América Latina y otras zonas del mundo, sino que no terminó siquiera su proyecto prioritario, El capital, que era apenas la primera parte de una obra monumental de análisis del mundo capitalista, proyectada en seis partes? ${ }^{7}$ Aún así, Marx dedicó una considerable cantidad de tiempo en sus últimos años de vida a estudiar diversas sociedades premodernas y no occidentales; dadas sus precarias condiciones de salud y su obsesividad por hacer editar solo aquello que estimaba muy desarrollado; es comprensible que no llegara a publicar nada al respecto?.

Pero, más allá de estas consideraciones, la interpretación planteada en el artículo del profesor Güendel sigue estereotipos que colocan a Marx en la filosofía especulativa de la historia propia de la Ilustración o, en el mejor de los casos, en el ambiente evolucionista del siglo XIX (algo así como un Spencer obrerista), con ello invisibilizó la ruptura epistemológica que introdujo la teoría de la historia de Marx. Así, Güendel cita con aprobación -califica como "excelente" al estudio del que lo extrae- el siguiente fragmento:

la influencia evolucionista hace ver la historia como un conjunto de etapas progresivas en forma lineal... pensaba erróneamente Marx que los procesos económicos estaban sujetos a ciclos de progreso, es decir que el próximo siempre sería mejor al actual (Güendel, 2011, p. 100).

6 Sobre el concepto de filosofía especulativa de la historia, como un tipo específico en el campo de la filosofía de la historia, consúltse Walsh (1968, p. 4-9).

7 Al respecto consúltese Mandel (1985, p. 25-26).

8 Consúltese Anderson (2010, p. 196-236). Riazanov, el gran editor de la obra marxiana, no entendió la importancia de estas notas suponiendo -desde una pespectiva eurocéntrica-que eran simple producto de una "inexcusable pedantería” por parte de Marx (Anderson, 2010, p. 197).

9 Véase Wheen (2000). 
El fragmento anterior logra sintetizar varios lugares comunes de una interpretación apegada al mecanicismo de la II Internacional, al que nos hemos referido páginas atrás. La visión de la historia como "etapas progresivas en forma lineal", donde "el próximo siempre sería mejor que el actual" es una caricatura de la Guerra Fría, teniendo en cuenta que desde sus textos tempranos, Marx le asignó una importancia fundamental a la praxis humana, tal como se puede apreciar en sus Tesis sobre Feuerbach, pero también en sus textos de análisis más coyunturales como El 18 brumario de Luis Bonaparte. Si bien en esa primera fase tendió a pensar la historia de modo lineal, no la veía como una fatalidad: el "progreso" debía ser conquistado por los sujetos interesados en la transformación histórica. No admitía ninguna predeterminación; lo que buscaba eran tendencias de la historia, que podrían llevar a distintos desenlaces $^{10}$. ¿Cuál progreso se puede encontrar en el paso del esclavismo al feudalismo, este último mucho menos productivo que su antecesor? ¿Cuántos siglos tardó Europa Occidental en pasar de un modo de producción a otro?

Por ejemplo, en uno de sus artículos de 1853 sobre la India, Marx dejó abierta la posibilidad de que la independencia de este país le llegaría a permitir salir del estancamiento al que le estaba induciendo el colonialismo británico:

Los indios no cosecharán los frutos de los nuevos elementos sociales esparcidos entre ellos por la burguesía británica, hasta que en la misma Gran Bretaña las clases dominantes sean reemplazadas por el proletariado industrial, o hasta que los mismos hindúes se hayan fortalecido suficientemente para liberarse totalmente del yugo inglés. En cualquier caso, podemos esperar ver, en un período más o menos remoto, la regeneración de ese gran e interesante país [...] La profunda hipocresía e inherente barbarie de la civilización burguesa queda revelada ante nuestros ojos al dejar su hogar, donde asume formas respetables, para ir a las colonias, donde va desnuda (Marx y Engels, 1979, p. 221) ${ }^{11}$.

10 Por supuesto, en el Manifiesto se plantea la revolución socialista como inminente. Esto se debe, por un lado, a que de hecho los movimientos revolucionarios de 1848 podían ser percibidos en el plazo inmediato como a punto de tomar el poder estatal en Europa central y occidental; por otro, a que el interés del texto no era solamente científico, sino que ante todo iba dirigido a militantes directamente implicados en esos movimientos.

11 El énfasis es mío. El carácter novedoso de este modo de abordar el problema del colonialismo en India ha sido recalcado por el célebre historiador indio Irfan Habib. Véanse sus Essays in Indian History. Towards a Marxist Perception (1995, p. 14-58). 
No solo resulta imposible pensar desde una "diferencia imperial" un pasaje como el anterior, sino que la historia aparece abierta a distintas posibilidades de despliegue: en este caso, por la revolución proletaria en el centro o por la revolución independentista en la periferia ${ }^{12}$.

Pero, si ya para los textos del joven Marx es abusivo hablar de una historia teleológica y de progreso necesario, en el caso del Marx maduro, resulta de plano absurdo. ¿Dónde estaba su supuesto optimismo en la inminencia del "progreso" socialista cuando cerró su Crítica al programa de Gotha con un desilusionado "dixi et salvavi animam meam"? La idea de progreso, ya de por sí problematizada por la dialéctica marxiana que caracteriza los movimientos históricos desde el desarrollo desigual, es explícitamente denunciada por Marx como ideología:

La llamada presentación histórica del desarrollo se basa, como regla, en el hecho de que la forma más reciente mira a las anteriores como pasos que llevan hacia ella, y puesto que sólo raramente y bajo condiciones bastante específicas es capaz de criticarse a sí misma -dejando de lado, por supuesto, los períodos históricos que se presentan a sí mismos como tiempos de decadencia-, siempre las concibe unilateralmente" (Marx, 1979 , p. 106).

Evidentemente, en 1848 Marx tenía como referente político las luchas de las clases obreras industriales europeas, y no pensó las contradicciones a nivel de sistema-mundo, pero esto fue cambiando en las décadas posteriores. De una visión lineal de la historia, Marx pasó a través de sus estudios sobre otros contextos no moderno-europeos, hacia su concepción plurilineal de la historia: la de una totalidad concreta que ya guarda poca similitud con la totalidad hegeliana. Sabemos, además, que Marx nunca pudo escribir su tratado sobre las relaciones internacionales, con lo cual sin duda hubiera delineado una teoría del sistema-mundo ${ }^{13}$.

Lejos de lo que sugerirían las posteriores simplificaciones doctrinarias, Marx recabó y utilizó una gigantesca cantidad de materiales empíricos, como se puede observar en textos como El capital o en sus Grundrisse, lo cual no sugiere un método de proyección de principios a priori -o, menos aún,

12 Véase Nimtz, 2002, p. 65-80.

13 Véase Wallerstein, 2001, p. 151-169. 
de prejuicios - sobre su campo de estudios. ¿Para qué molestarse tanto en estudiar la historia, si hubiera sido más fácil simplemente reiterar prejuicios desde un "lugar de enunciación de superioridad racial, moral, intelectual" (Güendel, 2011, p. 98)? La respuesta es muy sencilla: porque Marx, como investigador, fue elaborando su método científico de aproximación a la historia a lo largo de muchos años, y a partir de un estudio concienzudo de las fuentes con las que contaba —además de la reflexión categorial, claro está-. Esto, metodológicamente, no tiene nada que ver con las viejas filosofías especulativas de la historia con las que lo asocia el artículo de Güendel. Imputarle a Marx una visión "progresista" de la historia es tergiversar una trayectoria de investigación que fue nutriéndose no solamente de nuevos conocimientos empíricos, sino también de reformulaciones de la propia teoría a lo largo de los años.

La explicación de Güendel acerca de la falta de estudios de Marx sobre América Latina ${ }^{14}$ recae en que "para él, esta región del continente, al no denotar desarrollos capitalistas-industriales, no aparece como significativa dentro del sistema de relaciones internacionales que crea el capitalismo"

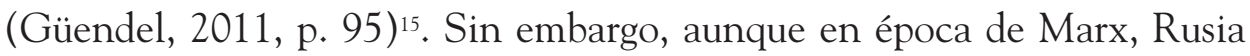
carecía de una industria significativa, ya entre 1858 y 1860 el futuro autor de El capital empezó a estudiar asiduamente la historia rusa ${ }^{16}$. Por supuesto, no cabe alegar eurocentrismo en este interés: desde el eurocentrismo los países eslavos no son europeos; con muchas dificultades lo serían acaso antiguas potencias imperiales como Portugal y España ${ }^{17}$.

De ese país no industrializado, lo que le llamó inicialmente la atención a Marx fue una situación no típica de relaciones sociales propiamente capitalistas: los movimientos de emancipación de los siervos, y la posibilidad de que esos movimientos llevaran eventualmente a una revolución que no llevara al modo de producción capitalista, ni tuviera que pasar por la "acumulación

14 Dicho sea de paso, Marx no habla de "América Latina" ni de "latinoamericanos", sino de procesos históricos específicos que hoy situamos bajo estas denominaciones geográficas, de modo que las generalizaciones que según Güendel se desprenden de los textos de Marx como "críticas a América Latina" no fueron formuladas por Marx, sino que son extrapolaciones elaboradas por este académico costarricense.

15 El énfasis es mío.

16 Véase Anderson, 2010, p. 52-56.

17 Véase Dussel, 2008, p. 190. Sobre la relación entre "Europa” y las etnias eslavas, véase. Žižek, 2002, p. 11-20. 
primitiva", sino a una forma de organización de gobierno comunitario. Este interés llevó a Marx a aprender la lengua rusa a partir de 1869, así como a mantener una intensa correspondencia con los populistas rusos ${ }^{18}$.

En menor medida, estudió también los problemas en torno a la emancipación nacional en Polonia y en Irlanda. A la primera la exaltó como uno de los factores en la fundación de la I Internacional ${ }^{19}$; sobre Irlanda dice, en 1867, que lo que dicho país necesitaba era: "1. Autogobierno e independencia de Inglaterra. 2. Revolución agraria. [...] 3. Aranceles de protección frente a Inglaterra" (Marx y Engels, 1979, p. 486-487)20. Estamos hablando de países no industriales; entonces, ¿realmente Marx era un evolucionista? Incluso concediendo que lo haya sido antes de 1856, a partir de ese año tal caracterización no tiene ningún sustento ${ }^{21}$.

Pero en el artículo que ha motivado esta réplica hay otra afirmación tanto más grave: la de que Marx formuló su teoría desde un lugar de superioridad racial. Por supuesto, esta afirmación sirve para completar el perfil de un típico positivista del siglo XIX y negar la ruptura científica de su concepción de la historia respecto a los consensos hegemónicos en la intelectualidad europea decimonónica. Es, además, una interpretación que supone a un Marx que nunca leyó a Hegel; es la caricatura del Marx que interpretaron en la II Internacional y en el estalinismo.

Específicamente, esta afirmación de racismo muestra un desconocimiento de la posición del Marx maduro respecto a los conflictos étnicos

18 Véase Anderson, 2010, p. 196-197.

19 Véase Anderson, 2010, p. 64-67 y 124-138.

20 Énfasis del original.

21 Pero parece ser una interpretación actualmente muy difundida. Recientemente de visita en Costa Rica, el teórico decolonial Ramón Grosfoguel criticó de nuevo a Marx por considerarlo "etapista". Para tal efecto, indicaba que en El capital la "acumulación originaria" es presentada como una etapa del pasado europeo, ya superada. Su crítica se basa, curiosamente, en el concepto marxista (de David Harvey) de acumulación por desposesión, para indicar el carácter estructural de la "acumulación originaria”. Sin embargo, si hubiera leído el siguiente capítulo (el XXV) hubiera podido observar cómo Marx teorizó sobre las particularidades de la imposición del capitalismo en las colonias, de un modo que no tiene nada de "etapista", sino que remite a condiciones históricas distintas a las europeas. De hecho, Marx rechazó explícitamente esa interpretación "etapista". Véase Dussel, 1990, p. 254. Grosfoguel termina por decir lo que ya Marx había sostenido, pero pretendiendo haberlo "descolonizado". Este tipo de críticas denota una búsqueda constante de ciertos autores por criticar a Marx desde ciertos prejuicios, sin haberlo leído suficientemente. Esta intervención (accesada el 16 de agosto de 2013) ha estado accesible en: http://www.youtube. $\mathrm{com} / \mathrm{watch} ? \mathrm{v}=\mathrm{jybdkb} 5 \mathrm{wATO} \&$ feature $=$ youtu.be 
de la segunda mitad del siglo XIX. Dicho sea de paso, y como recuerda Ahmad, quienes se quejan del estilo poco delicado con el que Marx se refirió a las sociedades premodernas y a las periféricas -en cuenta su artículo sobre Bolívar ${ }^{22}$ - dejan de lado que tampoco tuvo palabras precisamente agradables respecto a las burguesías europeas, ni a las potencias coloniales, ni a su misma Alemania natal, ni al campesinado occidental ${ }^{23}$; también en alguna ocasión afirmó que, en el capitalismo, las necesidades de los obreros industriales se "animalizan", lo cual no contradice que haya considerado al proletariado como el sujeto revolucionario por excelencia en dicho modo de producción ${ }^{24}$. Es inequívoco que el estilo de Marx no tiene que ver con que las sociedades a las que se refería fueran o no europeas; las acusaciones de racismo contra Marx provienen simplemente de una lectura sesgada ideologizada, sin duda alguna- de tales textos.

Hemos indicado que el socialista alemán apoyó las insurrecciones de 1857 en China y la India contra el Imperio Británico; que se alineó contra los ingleses a favor de los independentistas irlandeses, y que notó con gran aprobación el carácter revolucionario de los pueblos ruso y polaco. El reconocimiento de esos movimientos sociales, como factores de transformación, no remite ni al eurocentrismo, ni a la linealidad, ni mucho menos a la teleología; pero tampoco tiene nada que ver con temas raciales. Esto debería quedar claro por un conocido pasaje de El capital, donde Marx indica muy explícitamente que la esclavitud es estrictamente una relación social, sin ningún fundamento más que histórico:

Un negro es un negro. Sólo bajo determinadas condiciones se convierte en esclavo. Una máquina de hilar algodón es una máquina de hilar algodón. Sólo bajo determinadas condiciones se convierte en capital. [...] El capital es una relación social de producción. Es una relación histórica de producción (Marx, 2009, p. 957) ${ }^{25}$.

Este fragmento, originalmente publicado por Marx en 1849, y autocitado en El capital, precisamente en el capítulo sobre la colonización, indica el

22 Véase, por ejemplo, la cita de Azócar que presenta el profesor Güendel, 2011, p. 99.

23 Véase Ahmad, 2008, p. 224-225.

24 Véase Marx, 2002, p. 110.

25 Énfasis del original. 
carácter de producción sociohistórica de la sujeción étnica en las estructuras del capitalismo: lo decisivo del racismo no radica en ninguna característica fisiológica, como pretendía el racismo decimonónico. En el tercer tomo de $E l$ capital no solo se reitera esta idea, sino que Marx se burla de las ideas racistas de los esclavistas estadounidenses, comparándolas con las de los burgueses que suponen normal que los asalariados tengan amos que los hagan trabajar ${ }^{26}$ : es decir, planteaba que la emancipación de los esclavos negros era tan legítima y necesaria como la de los obreros de los países industriales.

Recordemos, finalmente, que desde inicios de la década de 1860, Marx apoyó sin reserva alguna a la lucha antiesclavista de la Guerra de Secesión estadounidense. A inicios de 1865, en la carta que él mismo redactó, la Internacional le expresó su apoyo al presidente Lincoln y a la causa antiesclavista de la guerra, criticando a la vez la inacción de la clase obrera norteña frente a la institución del esclavismo:

Mientras los trabajadores, el verdadero poder político del Norte, permitieron que la esclavitud profanase su propia república, mientras ante el negro, dominado y vendido sin su consentimiento, presumieron de que la mayor prerrogativa del trabajador de piel blanca era venderse y elegir su propio dueño, no fueron capaces de alcanzar la verdadera libertad del trabajo, ni de apoyar a sus hermanos europeos en su lucha por la emancipación, pero esta barrera al progreso ha sido barrida por el mar rojo de la guerra civil (Citado en Anderson, 2010, accesado el 2 de agosto de 2013 en: http://marxismocritico. com/2013/01/21/el-lincoln-de-spielberg/).

En síntesis, reducir a Karl Marx, particularmente después de 1856, a los lugares comunes de la hegemonía positivista-burguesa del siglo XIX -eurocentrismo, elogio y acriticidad del imperio; ideología del progreso; determinismo mecanicista; racismo-, o a una filosofía especulativa de la historia, solo puede hacerse violentando la integridad de su obra. Por el contrario, su concepción de la historia es un medio indispensable -no completo, pero sí necesario - para comprender, y eventualmente transformar, las asimetrías de nuestras sociedades periféricas.

26 Véase Marx, 2010, p. 493-494. 


\section{Perspectivismo y ciencia de la historia}

Finalmente, creo importante referirme a algunas anotaciones que pueden parecer marginales en el artículo de Güendel, pero que tienen una gran importancia en cuanto a la epistemología de la que parten sus valoraciones. Se afirma, por ejemplo, que "el materialismo histórico marxista es un discurso de conocimiento que presupone una interpretación particular del movimiento de la historia desde procesos materiales que se dan en Europa, los cuales, simplemente son producto del mismo lugar de enunciación: la diferencia imperial (Güendel, 2011, p. 97)”.

Hemos visto ya que desde la segunda mitad de los cincuentas, Marx no pretendió explicar la dinámica mundial desde el modelo de una Europa "adelantada" a las demás regiones del mundo; pero en fragmentos como el anterior, se asoma una perspectiva que, ya desde su punto de partida, es ajena e incluso opuesta a la dialéctica desarrollada por Marx. Es, efectivamente, el perspectivismo: una posición epistemológica según la cual todo conocimiento está limitado por la parcialidad de cada lugar, desde el cual los seres humanos producen sus conocimientos. Desde este tipo de planteamiento, no puede existir un conocimiento de carácter universal, sino solo conocimientos limitados a contextos sociohistóricos particulares.

El artículo de Güendel insiste en reducir los alcances de la teoría de la historia de Marx -más bien entendida como una filosofía especulativa de la historia-, sin diferenciar fases en la producción de este autor, a "una enunciación categorialmente eurocentrada e imperial”. Nótese que desde esta caracterización las categorías de Marx serían per se eurocentradas, aunque esto no se argumenta más allá. De ahí que, frente a ese supuesto eurocentrismo, Güendel afirme que "se requiere entonces de una teoría integral de interpretación desde la especificidad de esta 'sección' del mundo para dar cuenta de lo que significa y se logra a través de los procesos revolucionarios regionales" (Güendel, 2011, p. 103).

Así planteado, resultaría que Latinoamérica es tan particular que necesita de una teoría propia, y que no podría tampoco ser aplicada a otras regiones del mundo. Contra un universalismo abstracto -el del "Marx" descrito por Güendel—, habría que formular, según ese razonamiento, un particularismo igualmente abstracto. En la teoría de la historia formulada 
por Marx a partir de los Grundrisse, por el contrario, aparece una solución bien diferente a dicho dilema, que remite a la dialéctica de totalidad y parte. Retomemos como ejemplo el caso de la esclavitud en América, al cual el profesor costarricense se refiere en dos ocasiones para desestimar la capacidad explicativa de la teoría marxiana.

En este sentido, indica que

la aparente contradicción económico-social del capitalismo europeo al imponer en América la esclavitud, es decir, una forma precapitalista de relaciones de trabajo, nunca es entendida por Marx sino como parte de la misma lógica de constitución del capitalismo y el mercado mundial (Güendel, 2011, p. 96).

La sobrecrítica de Güendel busca aquí tirar al niño saludable con el agua sucia: precisamente en un pasaje como el que cita al respecto de este tema, se muestra una visión compleja de la historia, que nada tiene que ver con la ideología de progreso que le imputa. Marx vio claramente que el modo de producción capitalista coexiste con otros modos de producción y formas sociales distintos a él, pero los subsume en su propia dinámica ${ }^{27}$. O sea, aunque lo condena por ello, el mismo Güendel muestra cómo Marx no piensa la historia en términos de etapas que se suceden (como las filosofías especulativas de la historia de carácter "progresista"), sino de un modo complejo y dialécticamente contradictorio.

Esta articulación de modos de producción, categorizada en los Grundrisse como formación económico-social, es la que permite aprehender concretamente sociedades históricas sin ceder a un historicismo conceptualmente vacío. En último término, el moderno sistema-mundo - una categoría asumida por el artículo de Güendel — es una estructura de formaciones económico-sociales, cuya totalización radica en el modo de producción capitalista: Immanuel Wallerstein, quien ha apostado por la posibilidad de una ciencia de la historia, es muy claro en cuanto a que lo fundamental de su aparato categorial se lo debe a la teoría de la historia de Marx ${ }^{28}$.

Volviendo al tema de la esclavitud, el artículo de Güendel afirma que la revolución haitiana es ininterpretable por al teoría eurocéntrica ${ }^{29}$.

27 Véase Marx, 2009.

28 Véase Wallerstein, 2004.

29 Véase Güendel, 2011, p 104. 
Considero que esta afirmación es correcta, y ello habla precisamente en favor del carácter no eurocéntrico de la teoría de Marx: ya en 1938, C.L.R. James había aplicado un aparato categorial marxiano para explicar dicha revolución, y pocos años después Eric Williams, sin tratar directamente sobre Haití, explicaba en su Capitalism and Slavery el desarrollo capitalista del esclavismo en el caribe británico ${ }^{30}$. Más recientemente, Eduardo Grüner ha explicado la revolución haitiana, con todo rigor historiográfico, desde una teoría de la lucha de clases en la tradición de la teoría de la historia de Marx ${ }^{31}$.

En la concepción marxiana de la historia, los conceptos se hallan siempre en tensión con la particularidad del contexto histórico, y de este depende la validez de dichos conceptos; así lo dicta el criterio metodológico materialista ${ }^{32}$. Por ello, este enfoque ha sido sumamente fructífero en un campo como la investigación histórica, donde la particularidad es ineludible, y ha arrojado importantes explicaciones respecto a sociedades del capitalismo central ${ }^{33}$, tanto como a las periféricas ${ }^{34}$ o las precapitalistas ${ }^{35}$. Difícilmente, se hubiera podido realizar investigación empírica sobre contextos tan disímiles desde unos conceptos universales abstractos (eurocéntricos); pero ciertamente no se hubiera podido explicar las lógicas sociales correspondientes desde el particularismo abstracto que se sigue de una visión perspectivista del conocimiento.

La visión de la historia del Marx maduro es necesaria, precisamente, porque rompe con cualquier "-centrismo", al desarrollar una teoría de la totalidad concreta, esto es, compleja y mediatizada, donde las particularidades no pueden ser reducidas a una universalidad abstracta. No podría insistir aquí demasiado en que es la base, en términos contemporáneos, de una teoría del sistema-mundo. Es una teoría de una totalidad que puede ser conocida, aunque sea aproximativamente, y en la que la parcialidad del

30 Véase James, 1989 y Williams, 2011.

31 Véase Grüner, 2010.

32 Véase, Hobsbawn, 2004, p. 148-162.

33 En este sentido, valga recordar los trabajos de historiadores como E.P. Thompson y Hobsbawm. Véase Kaye, 1989, p. 121-198.

34 Además de autores como los mencionados para el caso de la esclavitud americana, es el caso de las interpretaciones de los historiadores subalternistas indios durante los setentas y ochentas. Véase, Arnold, D. y Hardiman, D, 1994.

35 Por ejemplo, en historiadores como Dobb, Hill y Hilton. Véase Kaye,1989, p. 23-120. 
conocimiento humano no implica una incapacidad de aprehender al objeto de conocimiento - pues este no es un simple receptáculo pasivo de relaciones discursivas-, mientras que, para el perspectivismo que insinúa el profesor Güendel, el conocimiento es una operación enmarcada por los discursos que lo producen. Desde una concepción perspectivista, todo conocimiento sería, en último término, ideología.

Así, si en los años noventas, Fredric Jameson observaba que para el imaginario occidental era más verosímil imaginar el fin de la humanidad que un cambio más modesto en las relaciones sociales, hoy, este tipo de epistemologías sostiene que no se puede conocer la historia, o, más aún, que no se puede conocer las estructuras del mundo en general. Desde esta concepción, de raíces nietzscheano-weberianas, la historia se disuelve en discursos verosímiles -en mera historiografía-; a pesar del populismo epistémico que hoy acompaña a estas posiciones, pareciera ser poco lo que puedan aportar a la explicación de las relaciones profundas que estructuran eso que llamamos Latinoamérica. En este sentido, muy poco se gana al cambiar a Marx por Nietzsche ${ }^{36}$.

Adicionalmente, cuando el artículo de Güendel afirma que "más que por condiciones estructurales económico-políticas, las condiciones revolucionarias regionales están constituidas por cotidianidades disociadas dentro de espacios-tiempos comunitarios y colectivos" (Güendel, 2011, p. 104), primeramente hace una falsa contraposición entre lo estructural y lo cotidiano (tanto la política como la economía tienen sus cotidianidades), y posteriormente impone unilateralmente -de modo no dialéctico- el segundo término sobre el primero, pasando a una visión que se enmarca en lo que el fundamental teórico periférico Samir Amin ha denominado culturalismo ${ }^{37}$. En último término, la negación de la posibilidad de conceptualizar a Latinoamérica desde una teoría de la historia viene aparejada con un fetichismo de la diferencia, en este caso de la diferencia cultural ${ }^{38}$.

36 En contraste, nótese cómo Dussel ha enriquecido las discusiones sobre la dependencia económica latinoamericana a partir de su lectura del Marx maduro. Véase Dussel, 1988, p. 312-361.

37 Véase Amin, 2009.

38 Para el análisis y crítica de este tipo de planteamientos, véase Grüner, 2002. 


\section{Epílogo}

El artículo del profesor Güendel basa el grueso de su argumentación en interpretaciones de autores -Chavolla, Azocar, Fillipi- cuyas lecturas de Marx parten de graves problemas metodológicos y teóricos. En cuanto a lo metodológico, aislan de su contexto textos del autor, para luego aventurar desde esa lectura fragmentaria generalizaciones sobre su obra completa. En cuanto a los de fondo, teóricos, coinciden en su lectura de Marx como un autor no dialéctico: una interpretación rebatida desde las primeras décadas del siglo pasado, y que no puede dar cuenta de la obra del socialista alemán, en particular al contrastarse con textos como los Manuscritos económico-filosóficos o los Grundrisse.

El Marx "imperial” y "eurocéntrico" del que habla el artículo de Hermann Güendel, basado en dichos autores, es el de los manuales de propaganda, tanto estalinista como anticomunista; no tiene nada que ver con el investigador que desarrolló las categorías fundamentales para el estudio científico de la historia. Si ya desde su juventud Marx fue un investigador riguroso, su producción de madurez es en particular importante para comprender América Latina en su relación con el sistema-mundo. Este, como indica Néstor Kohan:

Es el Marx imprescindible para 'traducir' y utilizar en nuestra actual América Latina, a inicios del siglo XXI. No el seco, gris e inoperante de los manuales, sino aquel apasionado político e investigador -sí, al mismo tiempo- que tiene la suficiente lucidez como para volver sobre sus pisadas y reconfigurar su teoría de la historia (Kohan, s.f., p. 238).

En este mismo sentido, uno de los principales filósofos latinoamericanos de la liberación, quien ha realizado varios estudios de primera mano sobre la producción marxiana, ha estimado que

La filosofía de la liberación latinoamericana tiene mucho que aprender de Marx. La 'ciencia' de Marx fue 'Filosofía de la liberación' del trabajo vivo alienado en el capital como trabajo asalariado en la Europa de la segunda mitad del siglo XIX. [/] Hoy, nuestra 'filosofía de la liberación' debe ser también la ciencia del trabajo vivo alienado de las clases, de los pueblos 
periféricos, subdesarrollados, del llamado Tercer Mundo, que luchan en los procesos nacionales y populares de liberación contra el capitalismo central y periférico, a fines del siglo XX (Dussel, 1988, p. 310-311).

Pensar la transformación social en Latinoamérica implica un trabajo muy arduo. Pero, ciertamente, será mucho más arduo si empezamos por renunciar a los mejores aportes científicos con los que ya disponemos para conocer nuestra realidad en el seno del sistema-mundo.

\section{Referencias}

Ahmad, A. (2008). In Theory. Classes, Nations, Literatures. Londres-Nueva York: Verso. Althusser, L. et al. (1972). Polémica sobre marxismo y humanismo. México: Siglo XXI.

Amin, S. (2009). Eurocentrism. Modernity, Religion and Democracy. A Critique of Eurocentrism and Culturalism. Nueva York: Monthly Review Press.

Anderson, K. (2010). Marx at the Margins. On Nationalism, Ethnicity and Non-Western Societies. Chicago: Chicago University Press. http://dx.doi.org/10.7208/ chicago/9780226019840.001.0001

Anderson, K. (2013). "El 'Lincoln' de Spielberg, Karl Marx y la Segunda Revolución Americana", accesado el 2 de agosto de 2013 en: http://marxismocritico.com/2013/01/21/ el-lincoln-de-spielberg/

Arnold, D.y Hardiman, D. (1994). Subaltern Studies VIII. Essays in Honour of Ranajit Guha. Nueva Delhi: Oxford University Press.

Bartolovich, C. y Lazarus, N. (2002). Marxism, Modernity and Postcolonial Studies. Cambridge: Cambridge University Press. http://dx.doi.org/10.1017/CBO9780511483158

Dussel, E. (1985) La producción teórica de Marx. Un comentario a los Grundrisse. México: Siglo XXI.

Dussel, E. (1988). Hacia un Marx desconocido. Un comentario de los Manuscritos del 61-63. México: Siglo XXI.

Dussel, E. (1990). El último Marx (1863-1882) y la liberación latinoamericana. México: Siglo XXI.

Dussel, E. (2008). 1492. El encubrimiento del otro. Hacia el origen del "Mito de la modernidad". La Paz: Biblioteca Indígena.

Grüner, E. (2002). El fin de las pequeñas historias. De los estudios culturales al retorno (imposible) de lo trágico, Bs. Aires: Paidós.

Grüner, E. (2010). La oscuridad y las luces. Capitalismo, cultura y revolución. Bs. Aires: EDHASA.

Güendel, H. (2011). "Marx sobre América Latina, revisión crítica de una enunciación eurocentrada". Revista Praxis (67), 91-106.

Habib, I. (1995). Essays in Indian History. Towards a Marxist Perception. Nueva Delhi: Tulika. Hobsbawm, E. (2004). Sobre la historia. Barcelona: Crítica. 
James, C.L.R. (1989). The Black Jacobins: Toussaint L'Ouverture and the San Domingo Revolution. Nueva York: Vintage.

Kaye, H. (1989). Los historiadores marxistas británicos: un análisis introductorio. Zaragoza: Universidad de Zaragoza.

Kohan, N. (s.f.). Simón Bolivar y nuestra independencia. Una lectura latinoamericana. Bs. Aires: La Rosa Blindada.

Kohan, N. (1998). Marx en su (tercer) mundo. Hacia un socialismo no colonizado. Bs. Aires: Biblos.

Korsch, K. (1971). Marxismo y filosofía. México: ERA.

Mandel, E. (1985). "El capital". Cien años de controversias en torno a la obra de Karl Marx. México: Siglo XXI.

Marx, K. (2001). Manuscritos de economía y filosofía. Madrid: Alianza.

Marx, K. (2009). El capital, tomo I. México: Siglo XXI.

Marx, K. (2010). El capital, tomo III. México: Siglo XXI.

Marx, K. (2009) El capital, libro I capítulo VI (inédito). Resultados del proceso inmediato de producción. México: Siglo XXI.

Marx, K. y Engels, F. (1978). Materiales para la historia de América Latina. México: Pasado y Presente.

Marx, K. y Engels, F. (1979). Collected Works, 52 tomos. Moscú: Progreso.

Musto, M. (coord.) (2011). Tras las huellas de un fantasma. La actualidad de Karl Marx. México: Siglo XXI.

Said, E. (1990). Orientalismo. Madrid: Prodhufi.

Wallerstein, I. (2001). "Marx and Underdevelopment". Unthinking Social Science. Philadelphia: Temple University Press.

Wallerstein, I. (2004). World-Systems Analysis: an Introduction. Durham-Londres: Duke University Press.

Walsh, W.H. (1968). Introducción a la filosofía de la historia.México: Siglo XXI.

Wheen, F. (2000). Karl Marx. Madrid: Debate.

Williams, E. (2011). Capitalismo y esclavitud. Madrid: Traficantes de Sueños.

Žižek, S. (2002). El frágil absoluto. Valencia: Pre-textos. 